\title{
Rethinking Stigma and Gambling
}

\author{
Critical Gambling Studies Blog Entry by Helen Keane
}

Visit an interactive version of this blog at:

https://criticalgamblingstudies.blogspot.com/2019/09/rethinking-stigma-and-gambling.html

Stigma is an unusually successful sociological concept. Not only has it flourished in public health and social psychology by capturing the powerful effects of social exclusion on wellbeing, it has become part of vernacular language. The downside of this success is a loss of precision and diminishment of critical incisiveness. Rather than designating a political and social relationship based on the exercise of power, stigma is commonly used to refer to general reactions of social disapproval and/or the negative associations linked to particular conditions or identities. The critical element that remains intact is the idea of unjustified disapproval: to say that an attribute is stigmatised is to claim that is wrongly subject to discrimination or devaluation.

However, stigma has recently benefitted from revitalising sociological attention and reformation. In the context of contemporary problems of inequality and injustice, Imogen Tyler and Tom Slater have highlighted an urgent need for a 'richer and fuller account of stigma as a cultural and political economy' (2018, p. 721). In a discussion of the 'abject subjectivities' related to addiction, Suzanne Fraser and colleagues argue that stigma should be recognised as a politically productive process rather than a stable marker of pre-existing difference (2017). These accounts of stigma raise questions about how the concept is deployed in the literature on 'problem gambling', and the effects of this deployment.

In public gambling discourse there is a consensus that gambling problems are stigmatised and that stigma is an important source of harm for those with gambling problems. In 2015 the US National Council on Problem Gambling stated in its strategic plan that 'we will work to overcome the stigma and misconceptions associated with problem gambling by identifying public misconceptions about problem gambling, developing messaging dispelling misconceptions, and developing communications material that highlights successful recovery' (cited in Feeney \& Whyte, 2016, p. 3). See also reports by the Victorian Responsible Gambling Foundation (2015) and the Australian National University's Centre for Gambling Research (Carroll et al., 2013). The approach to problem gambling stigma in the research literature is primarily psychological and cognitive. It draws heavily from work on the stigmatisation of mental health conditions. Stigma is understood as comprising a number of different forms of belief and reaction: 'public stigma' is the reaction that 'the general population' or 'society' has to the person with the stigmatised and devalued condition, 'perceived stigma' is the belief that other people hold stigmatising ideas and 'self-stigma' is the internalisation of negative societal beliefs, resulting in diminished self-esteem and self-efficacy (see Corrigan 2004; Watson et al., 2007; Barney et al., 2006). 
Adopting these concepts, problem gambling research has taken two main approaches: 1) Comparisons of the intensity of public stigma associated with problem gambling with that associated with other conditions, usually mental health conditions including substance use disorders; 2) The investigation of stigma, both perceived and internalised, as a barrier to 'helpseeking' for those experiencing problems with their gambling.

Qualitative research has also explored the feelings and beliefs of people experiencing gambling problems, highlighting individual stories of shame and negative judgment. Overall the stigma research demonstrates that people with gambling problems tend to be blamed for their predicament and are stereotyped as foolish, weak and greedy. In addition, people with gambling problems report high levels of perceived stigma and self-stigma, which lead to secrecy as a coping mechanism and therefore lead to delayed help-seeking. Thus 'stigma-reduction' emerges as an important public health response to gambling, via strategies such as education, increased community contact and the promotion of positive images.

There is no doubt that reducing the discrimination and shame faced by people struggling with gambling is a laudable and important goal with numerous positive effects. But the conventional approach to gambling stigma tends to reproduce medicalised understandings of the problem gambler and depoliticised notions of stigma. The 'problem gambler' or 'the person with a gambling problem' who attracts stigma is taken for granted as a pre-existing category of individual, a 'pathological subject' of consumption in Gerda Reith's words (2007). The comparison with health conditions such as Schizophrenia which frequently features in the literature reinforces the idea that problem gambling is a disorder located within the individual. The emphasis on help-seeking as the desired and healthy behaviour that is undermined by stigma is part of this process of medicalisation. Within a health problem framework, the provision of therapeutic interventions such as counselling and treatment emerges as the most rational and humane response to harm.

While gambling stigma discourse is premised on the view that disparaging stereotypes of problem gamblers are unjustified and harmful, it does not question the categorisation of gamblers into those who have failed to maintain self-control and those who are able to successfully gamble within the acceptable parameters of recreation. The problem gambler is by definition an individual who has turned gambling into a problem, as opposed to 'gamblers' - those who practice unproblematic gambling. Therefore while the literature on stigma often highlights the negative effects of responsible gambling campaigns, it risks reproducing the same individualising process in which gambling is bracketed as a neutral and abstract practice.

Targeting the issue of 'public stigma' also locates the harms of gambling within the mistaken beliefs of an ill-defined and presumably unenlightened 'general population' or 'public' who regard problem gamblers as irresponsible failures. Family and friends are also often identified as the sources of perceived stigma and stigmatising views, especially in qualitative research with 
gamblers and counsellors. In both cases however, questions of power, central to the sociological understanding of stigmatising processes, are muted.

What is obscured is the political economy of gambling in countries like Australia where it is an enormously profitable state supported industry and source of tax revenue. As Peter Adams, Angela Rintoul, Charles Livingstone and others have argued gambling, especially EGMs, operate as a ruthlessly efficient and targeted 'extractive economy' in which losses and harms are concentrated in areas of social disadvantage $(2008,2013)$. In her analysis of gambling in everyday life (2019), Fiona Nicoll identifies 'the problem gambler' as the scapegoat who is sacrificed to enable the profits and social benefits enjoyed by governments and businesses to continue. The stigmatisation of problem gamblers as scapegoated subjects is part of a social process inherent to the operation of gambling, rather than an external feature that can be ameliorated through education.

The stigmatisation of problem gambling is intimately tied to the production of poverty as individual failure within an economy of neoliberal capitalist accumulation. It is a profoundly material process which both exacerbates and justifies inequality. In this context, psychologised and cognitive versions of stigma have a limited ability to provide insight into the suffering produced by the systems and structures of gambling. Not least, the public health vision of stigma reduction risks misidentifying family and community members as perpetrators of harm rather than recognising collective experiences of deprivation and loss.

\section{$\underline{\text { References }}$}

Adams, P. J. (2007). Gambling, freedom and democracy. Routledge.

Barney, L. J., Griffiths, K. M., Jorm, A. F., \& Christensen, H. (2006). Stigma about depression and its impact on help-seeking intentions. Australian \& New Zealand Journal of Psychiatry, 40(1), 51-54.

Carroll, A., Rodgers, B., Davidson, T., \& Sims, S. (2013). Stigma and help-seeking for gambling problems. Australian National University.

Corrigan, P. (2004). How stigma interferes with mental health care. American psychologist, 59(7), 614-625.

Feeney, D. \& Whyte, K. (2016). Public opinion on problem gambling: Myths \& misconceptions. National Council on Problem Gambling.

Fraser, S., Pienaar, K., Dilkes-Frayne, E., Moore, D., Kokanovic, R., Treloar, C., \& Dunlop, A. (2017). Addiction stigma and the biopolitics of liberal modernity: A qualitative analysis. International Journal of Drug Policy, 44, 192-201.

Hing, N., Russell, A., Nuske, E., \& Gainsbury, S. (2015). The stigma of problem gambling: Causes, characteristics and consequences. Melbourne: Victorian Responsible Gambling Foundation.

Nicoll, F. (2019). Gambling in everyday life. Routledge. 
Reith, G. (2007). Gambling and the contradictions of consumption: A genealogy of the "pathological" subject. American Behavioral Scientist, 51(1), 33-55.

Rintoul, A. C., Livingstone, C., Mellor, A. P., \& Jolley, D. (2013). Modelling vulnerability to gambling related harm: How disadvantage predicts gambling losses. Addiction Research \& Theory, 21(4), 329-338.

Tyler, I. and Slater, T. (2018). Rethinking the sociology of stigma. The Sociological Review Monographs, 66(4): 721-743.

Watson, A. C., Corrigan, P., Larson, J. E., \& Sells, M. (2007). Self-stigma in people with mental illness. Schizophrenia Bulletin, 33(6), 1312-1318. 